\title{
Estimation of conservation value of myrtle (Myrtus communis) using a contingent valuation method: a case study in a Dooreh forest area, Lorestan Province, Iran
}

\author{
Neda Amiri ${ }^{* *}$, Seyed F. Emadian², Asghar Fallah³ ${ }^{3}$ Kamran Adeli ${ }^{4}$ and Hamid Amirnejad ${ }^{5}$
}

\begin{abstract}
Background: Around 2000 plant species occur naturally in Lorestan Province of which 250 species are medicinal and myrtle is one of them. Myrtle is a shrub whose leaves and fruits have medicinal value and thus, if managed and harvested properly, could produce sustained economic benefits. In recent years, however, over half of the myrtle site areas was destroyed, due to inappropriate management and excessive harvesting practices. Thus, coming up with a practical harvesting approach along with identifying those factors damaging the sites, seems to be very crucial.

Methods: In our investigation, we calculated the conservation value per hectare of myrtle in the Dooreh forest area in Lorestan Province. Using the Contingent Valuation (CV) and Double Bounded Dichotomous Choice (DBDC) methods, we determined the willingness to pay (WTP) for myrtle conservation. The WTP was estimated with a logit model for which indices were obtained based on a maximum precision criterion.

Results: The results showed that 86.67 per cent of people were willing to pay for the conservation of these myrtle sites. Average monthly WTP per family was calculated as $\$ 0.79$. The annual conservation value in terms of WTP for the preservation of the myrtle sites in Dooreh was estimated as $\$ 102,525$. Among the variables of the model presented, education had a positive impact, while the amount proposed for payment and family size had a negative impact on the WTP.

Conclusions: Our estimate of the value of myrtle conservation should provide justification for policy makers and decision making bodies of natural resources to implement policies in order to conserve the natural sites of this species more effectively.
\end{abstract}

Keywords: Conservation value, Myrtle, Contingent valuation method, Double Bounded Dichotomous method, Logit model

\section{Background}

Non-timber forest products are goods of biological origin other than timber, derived from forests, other wooded areas and trees outside forests (FAO Forestry 1999). In this context non-timber forest products include all kinds of animals, resin, tannin, medicinal and industrial plants and non-food products including materials or plant parts having medicinal properties, are edible and of industrial use (Noubissie et al. 2008). In recent years, issues related to non-timber forest

\footnotetext{
* Correspondence: amiri.neda90@yahoo.com

'Department of Forestry, Sari Agricultural and Natural Resource University, Sari, Iran Full list of author information is available at the end of the article
}

products, particularly the conservation of their natural habitat as well as their production, has attracted considerable interest in the world. The main reasons are the role of these products in providing livelihood and food for rural communities in order to reduce poverty along with supporting various environmental goals such as conservation of biodiversity (FAO Forestry 1999). Nontimber forest products (NTFPs) are accepted as a veritable means of achieving poverty alleviation because of their role in sustaining this livelihood, for food security and environmental objectives such as biodiversity conservation (FAO Forestry 1999). 
Valuation of NTFPs has received a great deal of attention (Lindal 1994). Many attempts have been made to value these non-marketed forest products to their full extent, especially the NTFPs. Extraction and increased trade of NTFPs has been advocated as an alternative to timber-focused utilization on the grounds that it could be pursued without causing tropical deforestation. Consequently, NTFPs are thought to be capable of playing a constructive role in forest conservation and development. This assumes that their harvest, even at a commercial level, would have little or no adverse ecological impact on a forest. This can be questioned, however, since the impact on the forest ecosystem of an increase in harvesting NTFPs is not fully known (Gunatilake et al. 2006; Peters 1994). Lescuyer (1996) argues that the establishment of a monetary value for each NTFPs leads to a change in the modes of use of the resource which, in turn, can cause or accelerate a process of restrictive appropriation of these resources. In many parts of the world, NTFPs provide off-farm employment to a large part of the rural population and accounts for a considerable share of household income. These resources are essential, especially for the rural poor and women, and may, in some cases, provide them with the only source of personal income (Rodda 1991; Falconer 1996). But economic problems may sometimes result in increasing the harvest of those NTFPs that have higher values, particularly those that can be sold on the international market. This is the kind of situation that may sometimes result in very high costs in terms of damage to forest ecosystems (Kengen 1997).

Conservation valuation seeks to create awareness about the need for decisions to optimize the economic management of resources and assists the development of a strategy for sustainable development in a region. Valuation of environmental services and functions is important for a number of reasons, such as: 1) recognizing and understanding of environmental and ecological interests by humans, 2) providing environmental issues to decision makers and country planning experts and 3) providing the link between economic policies and income derived from natural resources.

Economic valuation of natural and environmental resources includes two categories, i.e., use values and nonuse values (Pearce and Pearce 2001; Molaei 2009). Use values are associated with the consumption of products, while non-use values are related to enhancement of their utility to people without direct consumption of the products. Non-use values which reflect the concept of conservation consist of existence values, bequest values and option values. Existence value refers to the intrinsic value of a resource, even if people have never seen or used the resource (Torras 2000). Bequest value or future generation value is the desirability resulting from knowledge in preserving natural resources for future generations (Pearce and Pearce 2001). Option value measures the preference of individuals to preserve natural resources for possible future use (Lee and Han 2002). Alternatively, existence value can be considered the willingness of a society to pay for the conservation of natural resources, bequest value may be understood as the willingness to pay (WTP) for conservation of resources for the benefit of future generations, while option value can be defined as the willingness of society to pay for the conservation of resources for possible future use (Lee and Han 2002).

Researchers have attempted to estimate forest conservation values using various approaches. For example, Echeverria et al. (1995) estimated the value of existence benefits in Costa Rica's forests, based on a Contingent Valuation (CV) method and came up with a value of $\$ 238$ per hectare of forest per year. Lehtonen et al. (2003) estimated the average conservation value of forests in southern Finland in terms of the willingness to pay at $\$ 23.80$ per household per year, using $\mathrm{CV}$ in conjunction with Double Bounded Dichotomous questionnaires and a logit regression model. In another study, Leong et al. (2005) studied the conservation value of forests in mountainous areas of Malaysia and estimated conservation values ranging from 20 to 27 Ringgits per individual respondent. Gurluk (2006) used a Contingent Valuation approach to study the value of ecosystem services in a region in Turkey and estimated it at $\$ 76.94$ per year per household. Tao et al. (2012), also using a $\mathrm{CV}$ method, estimated the annual household willingness to pay for conservation of Heshui forest ecosystems in China's Jiangshi Province at 238 Yuan per year. Molaei in (2009) used a Contingent Valuation method to assess the conservation value of Arasbaran forest ecosystems and showed that $81.7 \%$ of the people from this area were willing to pay some money for conservation of the forest ecosystem. They estimated the annual WTP for the conservation of these forest ecosystems at about $\$ 3.31$ per household and $\$ 197.32^{1}$ per hectare of forest land. Peron and Esmaeili (2010) used the Contingent Valuation approach to estimate the conservation value of mangrove forests in Hormozgan province in Iran and found that $92 \%$ of the respondents were willing to pay some money to conserve these mangrove forests. They estimated the average conservation value per individual at $\$ 12.65$ and at $\$ 76.94$ per hectare of forest.

Although many investigations have been carried out to estimate the conservation value of forest resources, studies on the conservation valuation of forest resources for non-timber forest products, similar to ours, are very limited. For example, Chukwuone and Okorji (2008) used $\mathrm{CV}$ method to estimate annual willingness to pay per person for systematic management of forest communities in 
Nigeria and concluded that people were willing to pay $\$ 55.40$ for conservation of their forest for non-timber forest products. Khosravi and Sabouhi (2011), used the same method to estimate the annual conservation value for all tamarisk trees in the Fahliyan riparian area in province of Fars in Iran at \$4588. In the same study they estimated the monthly conservation value of each tamarisk tree at $\$ 0.163$. Molaei and Kavousi Kelashmi (2011) using the same technique, but with a One-Half Bound format, estimated the conservation value of the chandelier lily at $\$ 0.192$ based on a linear model and $\$ 0.285$ with a logarithmic model.

Our investigation dealt with myrtle (Myrtus communis L.) forest sites in Dooreh, a city in Lorestan Province, Iran. Myrtle, as a non-timber forest product, is an evergreen medicinal plant. It belongs to the family Myrtaceae and is found naturally in many parts of the province. This valuable shrub forms dense populations at low elevations at some of its natural habitats. Given its ability to grow and develop in some unfavorable circumstances, such as warm climates, myrtle is one of those plants that plays a significant role in the conservation of its environmental habitat. This plant contains two important volatile oil substances, i.e., Myrtenol and Depantyn, which are very valuable to the pharmaceutical industry and thus, potentially myrtle can play an important role in the local economy (Makkizadeh Tafti et al. 2006). As well, this species, is of importance in maintaining environmental sustainability in semiarid regions. Because of its evergreen features it helps to make the landscape more attractive and aids the restoration of natural ecosystems (Salehnia 2008).

Unfortunately, due to excessive harvesting, dense natural stands of myrtle are nonexistent. However, reforestation and afforestation of this plant have been proposed as feasible options. These are effective strategies to increase employment, support the regional pharmaceutical industry and increase family incomes in the community (Mirabad et al. 2011). The Khorraman Pharmaceutical Company is operating as a monopoly for it is the only pharmaceutical industry in the province that uses myrtle oil extracts to produce herbal medicines such as Belfarol, Myrtol, Rectol and Aphtoplex. Each year, an average of nearly $120 \mathrm{t}$ of myrtle is harvested by rural people in the region and sold to this company, resulting in a significant increase in the income of rural households, accounting for 63.38 per cent of their total monthly income during the harvest months (Amiri 2013). Frequent and excessive harvesting of myrtle shrubs by villagers, without training and knowledge of the species and its proper harvesting operation, inflict a great deal of damage on the habitat of this species (Amiri, 2013). This is consistent with the earlier findings by Karimi (2012), who reported that nearly half of the myrtle habitat was destroyed or converted into agricultural lands and the remaining half showed a dramatic decline in productivity. Overall, observations on the distribution of myrtle in Dooreh and interviews conducted with local people, have shown that the most important factors contributing to the destruction of the myrtle forest sites in order of importance are: 1) a lack of sound management practices and/or management incompetence, 2) excessive harvesting practices by the Khorraman Pharmaceutical Company to produce herbal medicines, 3) excessive harvesting practices and management by villagers for personal consumption and burning of myrtle habitats for the purpose of changing myrtle sites into agricultural land, 4) improper harvest operations by unskilled individuals, 5) lack of expertise in conservation of myrtle forests and their management, 6) weather condition in recent years and 7) excessive harvesting of myrtle branches for feeding livestock (Amiri 2013) (Fig. 1).

The purpose of our study was to estimate the conservation value of the myrtle habitat in Dooreh in order to provide the means and justification for forest policy makers and managers to support conservation of the habitat of this species and to stop its current horrifying destruction. Clearly, due to its various benefits, more attention need to be devoted and resources allocated to restore these damaged and destroyed myrtle habitats.

\section{Methods}

\section{The study area}

Our investigation was conducted in a single stand of myrtle located in Dooreh, Lorestan province. The city is located in the western part of the province, $36 \mathrm{~km}$ from the provincial capital, Khorramabad, at longitude $48^{\circ} 02^{\prime} 17^{\prime \prime}$ and latitude $33^{\circ} 39^{\prime} 56^{\prime \prime}$, at an elevation of $1118 \mathrm{~m}$ (Fig. 2).

\section{Contingent valuation method}

We used a Contingent Valuation method (CVM) to estimate the conservation value of myrtle forests in the Dooreh area. In this method a hypothetical market is assumed in which contingent questionnaires are distributed among respondents and completed in their presence or delivered by mail. The respondents are asked about their Willingness to Pay (WTP) for the quality and level of improvement of environmental products, or about their Willingness to Accept (WTA) a loss from inflicting damage to their resources (Bohm 1972; Dahlberg 1974; Hanemann 1991; Bateman \& Willis 1999).

Double- bounded questionnaires are used to measure WTP. This method was first proposed in 1979 by Bishop and Heberlin (Venkatachalam 2003). In their approach, respondents were faced with a choice of either "Yes" or "No" with respect to a proposed price in a hypothetical market (Venkatachalam 2003). Hahnemann (1985) 

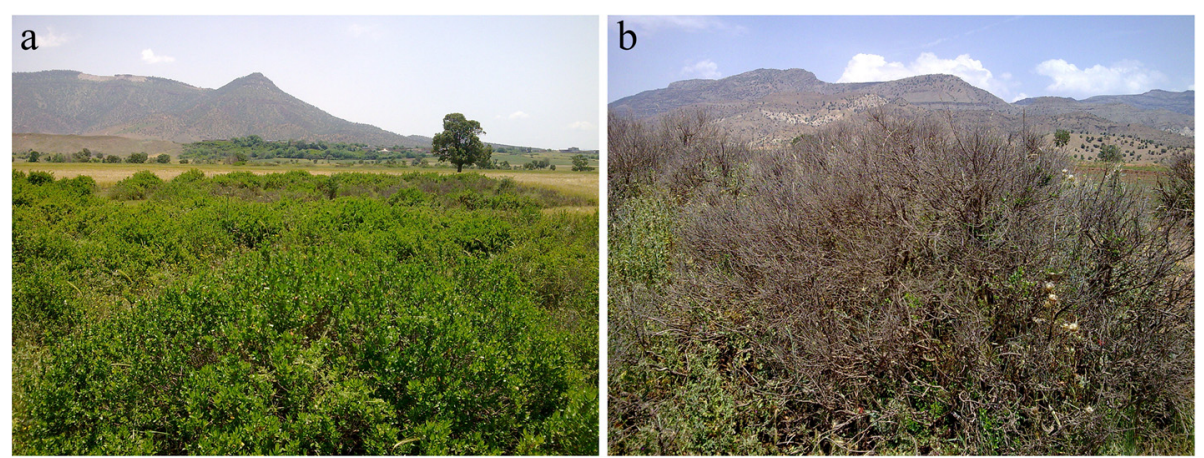

Fig. 1 Two contrasting myrtle habitats (a) healthy (b) damaged

modified and adjusted the Double- bounded Choice and proposed a Double- bounded Dichotomous Choice (DDC) method. This method requires determining one higher price proposed for the respondents in addition to the initially lower price proposal. Proposing the higher price depends on the initial responses or to their feedback on the initially proposed lower price (Venkatachalam 2003).

The first section of the questionnaire contained questions regarding socio-economic aspects of individual respondents, such as age, gender, occupation, education, place of residence, family size, income and membership in environmental organizations. The main questions, relating the WTP on the part of the respondents for conservation of myrtle in Dooreh, i.e., those related to the acceptance or rejection of the bids for willingness to pay, were introduced in a Double- bounded Dichotomous
Choice format. Forty questionnaires were initially completed in which open questions, without any proposed prices for willingness to pay, were asked. Thus, according to the preliminary information obtained from these questionnaires, the proposed prices were determined as 20,000 Rials for the main bid, 10,000 Rials for the lower and 30,000 Rials for the upper bid.

In order to derive the model for estimating WTP, it was assumed that the individual respondent either accepted the proposed price for conservation value to maximize his utility as described below (Eq. 1) or, alternatively, rejected it (Hanemann 1984).

$$
\mathrm{U}(1, \mathrm{Y}-\mathrm{A} ; \mathrm{S})+\epsilon_{1} \geq \mathrm{U}(0, \mathrm{Y} ; \mathrm{S})+\epsilon_{0}
$$

Where $\mathrm{U}$ is respondent, $Y$ his/her income, $A$ the proposed price, $S$ the socio-economic features affected

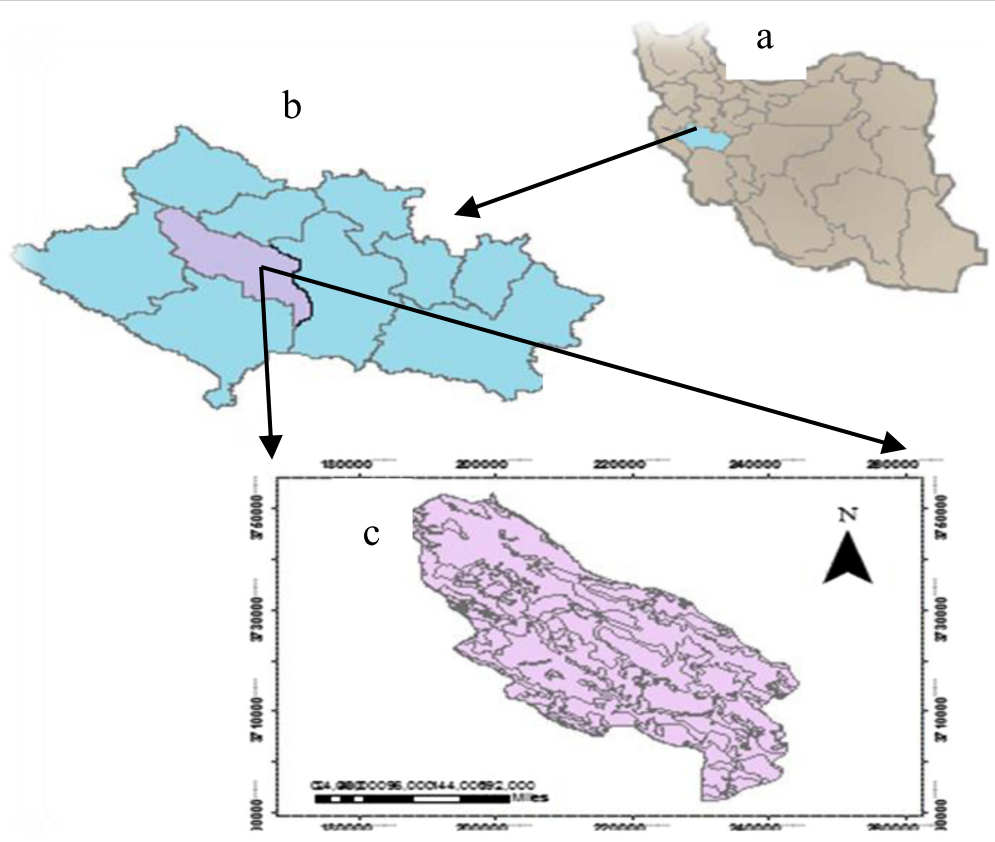

Fig. 2 The map of the study area: (a) Iran; (b) Province of Lorestan; (c) City of Dooreh 
by his/her taste and $\epsilon_{1}, \in_{0}$ are independent random variables with a zero mean. The utility difference $(\Delta \mathrm{U})$ due to using an environmental resource, is described as follows (Eq. 2):

$$
\Delta \mathrm{U}=U(1, Y-A ; S)-U(0, Y ; S)+\left(\epsilon_{1}-\epsilon_{0}\right)
$$

$\Delta \mathrm{U}>0$ implies the respondent maximizes his or her utility by saying "yes" and would agree to pay the amount for conservation of the myrtle (Park and Loomis 1996). The format of the double bounded questionnaire in CVM has a dependent variable with dual choice, which requires a qualitative choice model. In general, for studying regression models with a dual choice dependent variable, linear probability models, logit, probit and Tobit models are used (Nakhaei 1389). To investigate the effect of descriptive variables, such as economic and social factors, on the WTP, we used a logit regression model. The probability $\left(P_{i}\right)$ that the individual accepts an offer (A) based on the logit model, can be expressed as follows (Lee and Han 2002):

$$
\begin{aligned}
P_{i} & =F_{n}(\Delta U) \frac{1}{1+\exp (-\Delta U)} \\
& =\frac{1}{1+\exp \{-(\alpha-\beta \mathrm{A}+\gamma \mathrm{Y}+\theta \mathrm{S})\}}
\end{aligned}
$$

Where $F_{n}(\Delta U)$ is the cumulative distribution function with one standard logistic difference including some of the socio-economic factors. The coefficients $\theta, \gamma, \beta$ are estimates where $\theta$ and $\gamma>0$ and $\beta \leq 0$. (Lee and Han 2002). The expected WTP was calculated using logit models by actually integer numbers between 0 and the highest proposed value (Lehtonen et al., 2003). We opted for this method because it maintained the stability and compatibility of theoretical constraints, statistical efficiency and congregate ability (White and Lovett 1999).

The logit model utilizes maximum likelihood specifications and is the most common technique for estimating expected WTP (Piri et al., 2009). This was calculated by integer numbers between 0 and the highest proposed value: (Eq. 4).

$$
\begin{aligned}
E(W T P) & =\int_{0}^{\operatorname{Max} A} F_{n}(\Delta U) d A \\
& =\int_{0}^{\operatorname{MaxA}} \frac{1}{1+\exp \left[-\alpha^{*}+\beta A\right]}
\end{aligned}
$$

Where $E$ (WTP) is the expected amount of WTP and $\alpha^{*}$ (see Eq. 5) the interception adjustment value, added to the main interception $(\alpha)$ value, estimated after socioeconomic variables were inserted in the logit model.

$$
\alpha^{*}=(\alpha+\gamma Y+\theta S)
$$

Logit models may be developed as either linear or semi-logarithmic functions in order to estimate both use and conservation values. In the former model, the probability of accepting the proposed price is merely a function of the proposed price itself. However, in the latter model, the probability is a function of the proposed relative price over income for simplicity and convenience in computation, we used a linear logit model to compute the mean WTP (Molaei and Kavousi Kelashmi 2011).

To estimate the conservation value of the myrtle habitat, selected households from both urban and rural communities of Dooreh were asked to participate as part of our sample population. The required sample size for simple random sampling was calculated (Cochran 1977) for the $95 \%$ confidence interval with an allowed error of 4 \% (Eq. 6). This resulted in a sample size of 270 . However, to enhance accuracy, the number of household sampled in the area and participated in our study was increased to 300 (Eq. 6).

$$
n=\frac{t^{2} s^{2}}{d^{2}}=\frac{(1.96)^{2}(0.335)^{2}}{(0.04)^{2}}=269.45 \simeq 270
$$

where $n$ is the number of samples; $t$ is Student's $t$ value for $95 \%$ confidence interval, $s^{2}$ is the sample variance and $d$ is the allowed sampling error. Our interviews were focused on individuals who were independent in terms of income and when faced with the proposed amount, were able to make a decision easily. For the purpose of statistical analysis and mathematical calculations the parameters required for the logit model, we used SHAZAM and Excel.

\section{Results}

\section{Socio-economic status of respondents}

Descriptive statistics of the socio-economic characteristics of the respondents are presented in Table 1 . Of the total number of respondents, 208 (69.33\%) were male and $92(30.67 \%)$ were female. As this table shows the average age was 35 years, the number of years of education was 13, the average size of the household consisted of 4 people with a monthly household income of 15,000 Rials (\$.44), the proposed bid was 17,630 Rials (\$.52) and the environmental opinion was around 4.

\section{Conservation value of Myrtle}

Out of 300 respondents, 260 (86.67\%) were willing to pay something for the conservation of Myrtle habitats of Dooreh, while the other $40(13.33 \%)$ were not interested to pay anything (Table 2).

Of the 107 persons who did not accept the first offer of 20,000 Rials, 67 people were not willing to pay more 
Table 1 Statistical results of the socio-economic characteristics of the respondents (monetary values are in thousand Rials)

\begin{tabular}{lllllr}
\hline Variable & Mean & Standard deviation & Max & Min & Coefficient of variation \\
\hline Age & 34.97 & 11.58 & 70 & 20 & 0.331 \\
Sex & 1.307 & 0.4622 & 2 & 1 & 0.353 \\
Marital status & 1.657 & 0.456 & 2 & 1 & 0.275 \\
Education & 12.997 & 5.06 & 18 & 0 & 0.389 \\
Household size & 4 & 2.02 & 8 & 1 & 0.505 \\
Monthly income (In thousand Rials) & 15,000 & 6,030 & 2,5000 & 5,000 & 401.633 \\
BID Rials & 17,630 & 9,580 & 30,000 & 0 & 0.543 \\
Environmental opinion & 4.02 & 0.579 & 5 & 1 & 0.144 \\
\hline
\end{tabular}

than 10,000 Rials (\$0.29) and the remaining 40 individuals were not willing to pay anything.

Of the 193 people who had accepted the first offer of 20,000 Rials (\$0.59), 120 rejected the 30,000 Rials (\$0.88) bid and the rest agreed to pay 30,000 Rials (\$0.88).

Out of 73 persons who had accepted the first offer of 30,000 Rials (\$0.88), 19 were willing to pay up to 50,000 Rials (\$1.47), 15 people agreed to pay the maximum bid of 100,000 Rials (\$2.94), 14 persons were willing to pay a maximum amount of 150,000 Rials (\$4.41) and only four respondents showed a willingness to pay up to 200,000 Rials (\$5.88). The remaining 21 individuals did not want to exceed 30,000 Rials.

Forty of the respondents were not willing to pay for myrtle habitat conservation. When asked for their lack of interest, 60 per cent believed that it should be the responsibility of the government, not of individuals (Table 3 ).

The logit regression method provided the following model for the conservation value of the Dooreh myrtle forest:

$$
\mathrm{WTP}=\alpha_{0}+\alpha_{1} \mathrm{x}_{1}+\alpha_{2} \mathrm{x}_{2}+\alpha_{3} \mathrm{x}_{3}+\alpha_{4} \mathrm{x}_{4}+\mathrm{e}_{\mathrm{i}}
$$

where WTPi is the willingness of respondent $i$ to pay, $x_{1}$ represents education ( 0 for illiterate, 10 for below diploma, 12 for diploma, 14 for post diploma degree, 16 for bachelor degree, 18 for master degree and above); $x_{2}$ is household size, $x_{3}$ household income in thousand Rials $5,000 \quad(\$ 0.15), \quad 7,500 \quad(\$ 0.22), 12,500 \quad(\$ 0.37), \quad 17,500$ (\$0.51), 22,500 (\$0.67), 25,000 (\$0.73)) and $x_{4}$ represents the bids in Rials $(0,10,000$ (\$0.29), 20,000 (\$0.59), 30,000 (\$0.88)).

Table 4 shows the estimated coefficients, levels of statistical significance and the effect of descriptive variables of the logit model on the dependent variable (based on maximum likelihood estimation). In arriving at the final logit model those variables, not statistically significant but with coefficients of the expected sign, were eliminated in order to obtain a more accurate model (Table 4). In the end, we obtained the following model:

$$
\begin{aligned}
\mathrm{WTP}=1.970 & +0.049 \mathrm{E}-0.581 \mathrm{HS} \\
& +0.003 \mathrm{I}-0.002 \mathrm{SD}
\end{aligned}
$$

In this equation $\mathrm{E}$ is education, $\mathrm{HS}$ is Household Size, I is Income and SD is Suggested Donation.

The results also show that variables such as price, income and household size were effective in accepting the bids at less than the $10 \%$ statistical level. As well, it should be noted that the variables price and family size had a negative effect, while income and education had a positive effect on the WTP on the part of the respondents.

Moreover, the variables bid and income were statistically significant at the one per cent level of significance and were the most important factors in the WTP to conserve the myrtle forest. As the amount of the bid increased, the willingness to pay of people reduced substantially. This means that their elasticity to pay is inversely related with the price of perceived services provided, since their low

Table 2 Response to three proposed bids for the purpose of myrtle conservation

\begin{tabular}{lllll}
\hline Response & & BID 1 (20,000 Rials) & BID 2 (10,000 Rials) & BID 3 (30,000 Rials) \\
\hline Yes & Frequency & 193 & 67 & 73 \\
& Per cent & 64.33 & 22.33 & 24.33 \\
NO & Frequency & 107 & 40 & 120 \\
& Per cent & 35.63 & 13.33 & 40 \\
Total & Frequency & 300 & 107 & 193 \\
& Per cent & 100 & 35.67 & 64.33 \\
\hline
\end{tabular}


Table 3 Lack of willingness to pay

\begin{tabular}{lll}
\hline Lack of willingness to pay & Per cent & Frequency \\
\hline Due to financial reason & 12.5 & 5 \\
Must be paid by the permanent land users & 10 & 4 \\
Must be paid by the government & 60 & 24 \\
Local people must maintain the habitat & 17.5 & 7 \\
\hline
\end{tabular}

income levels have a negative effect on their support to conserve natural myrtle forest sites.

In terms of ranking the estimated coefficients, the second most important factor for accepting the bid for myrtle conservation was the income of the respondents. The higher their income, the higher their willingness to pay. This represents an indication of the status of well-being of the community, important from a development point of view. In other words, as income increased, the awareness on the part of people towards the environment became more positive and responsive who did not view the environment only from an economic stand point, but rather considered other aspects of it as well. At lower income levels, all resources were primarily seen as economic and revenue generators.

Another variable significantly related with the WTP was the size of the household. As this increased, the willingness to pay decreased considerably. The probability of rejecting the bids by large households was higher than that of household of smaller size, for households with more family members were less capable financially and thus had a relatively lower willingness to pay for myrtle conservation.

Education of the respondents had also an important effect on their willingness to pay. The proportion of respondents with university education was the highest at $33.49 \%$ of all participants. The level of education was directly related with household income, i.e., people with a high level of education had a more positive attitude toward the environment and the benefits that can be derived from it and, as a result, had a higher willingness to pay for the conservation of myrtle habitats.

In order to determine changes in the probability of the WTP in estimating the conservation value due to a one unit change in one of the independent variables, it was necessary to calculate their marginal effect. We also calculated elasticity to show the relative importance of the descriptive variables of the model in response to changes in the willingness to pay for the conservation of this myrtle forest ecosystem.

The proposed bid was the most important descriptive variable for determining the probability of willingness to pay for the conservation of myrtle forest resources in Dooreh. It showed that a one unit change in the amount of proposed bid changed the probability of accepting the bid by $1.8 \%$. Furthermore, due to the marginal effect of this variable, a one unit change in the amount of the proposed bid changed the probability of a positive response to the WTP by 0.0004534 in favor of the conservation of myrtle forest sites.

The estimated coefficient for the income variable was significant at the $1 \%$ statistical level. With its positive sign, as expected, it meant that a one per cent change in income, the probability of accepting the amount of the proposed bid would be changed by $1.732 \%$. Also, in terms of the marginal effect of this variable, a one unit change in the income of the respondent, the probability of accepting the proposed bid to conserve the myrtle forest resources of Dooreh, changed by $0.665 \times 10^{-3}$.

The estimated coefficient of household size was also significant at the $1 \%$ level and implied that a one unit change in the size of a household, the proposed bid for myrtle forest conservation changed by $1.26 \%$. In terms of marginal effect, a one unit change in household size changed the likelihood of a positive response on the part of the respondent in the WTP for myrtle forest conservation by 0.144 .

The estimated coefficient of education was significant at the $5 \%$ level. Therefore, one additional year spent on education, increased the probability of accepting the bid for conservation of myrtle forest by $0.284 \%$ unit. The marginal effect of this variable suggests that one additional year spent on formal education, increased the probability of reacting positively to the willingness to pay for myrtle forest conservation by 0.012 .

In addition, we calculated the McFadden coefficient of determination as 0.234 , suggesting that the explanatory variables of the model explained the dependent variable

Table 4 Estimated regression coefficient of the most effective variables of the logit model

\begin{tabular}{|c|c|c|c|c|c|c|}
\hline Variable & Estimated coefficient & Standard deviation & $t$-value & $p$ value & Elasticity & Marginal effect \\
\hline Constant coefficient & 1.97 & 1.097 & 1.796 & 0.073 & 0.881 & - \\
\hline Education $^{a}$ & 0.049 & 0.024 & 2.031 & 0.042 & 0.284 & $0.121 \times 10^{-1}$ \\
\hline Household size ${ }^{b}$ & -0.581 & 0.081 & -7.159 & 0 & -1.26 & -0.144 \\
\hline Monthly income ${ }^{\mathrm{b}}$ (in thousand Rials) & 0.0027 & 0.0003 & 8.998 & 0 & 1.732 & $0.665 \times 10^{-3}$ \\
\hline BID (Rials) & -0.0018 & 0.0002 & -9.122 & 0 & -1.8 & $-0.456 \times 10^{-3}$ \\
\hline
\end{tabular}

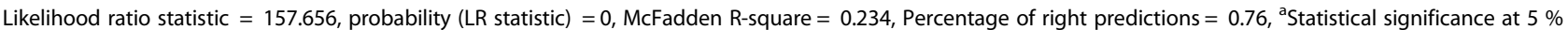
level. ${ }^{b}$ Statistical significance at $1 \%$ level 
very well. Another useful criterion for goodness of fit of the model was the classification of the respondents in two groups, i.e., those who accepted the bid for myrtle forest conservation and those who rejected it. The proportion of correct predictions of the model was 76 per cent, implying that $76 \%$ of the respondents indeed correctly answered "Yes" or "No" when asked about their willingness to pay.

The expected average WTP according to the logit model, using maximum likelihood was calculated by numerical integration in the range of zero to the maximum amount of the proposed bid as follows:

$$
\begin{aligned}
E(W T P) & =\int_{0}^{30000}\left(\frac{1}{1+\exp \{-(2.134299-0.001845 * B I D)\}}\right) d A \\
& =26820
\end{aligned}
$$

Based on Eq. (9), the expected willingness to pay per household for the conservation of myrtle stands in Dooreh, was estimated to be 26,820 Rials ( $\$ 0.79$ ) per month which meant that each family was willing to pay an equivalent amount of 321,840 Rials (\$9.47) per year to conserve the habitat of this species.

The overall conservation value of the myrtle forests in Dooreh (VMFD) was calculated using the following relationship:

$$
\mathrm{VMFD}=\mathrm{AAWH} \times \mathrm{NHD}
$$

In this equation, AAWH is the annual average of WTP per households and NHD is the number of households in Dooreh.

Given the 10,831 households currently living in Dooreh (Office of Lorestan provincial governor, 2013), we obtained ultimately the following conservation value:

$$
\begin{aligned}
\text { VMFD } & =(26,820 \times 12) \times 10831 \\
& =3,485,849,040 \text { Rials }
\end{aligned}
$$

Thus we estimate that the entire town of Dooreh is willing to pay 3.5 billion Rials (about $\$ 102,525$ ) annually for the conservation of their myrtle forest resources. Given that the remaining area of myrtle sites consist of only a little more than 8 ha, our final estimate of the conservation value of myrtle resources per hectare in Dooreh is:

$$
\begin{aligned}
\text { VMFD } / \text { ha } & =321840 \times 10831 \div 8.2175 \\
& =424,198,240 \text { Rials }
\end{aligned}
$$

Hence, the annual conservation value per hectare of the myrtle forest resources in Dooreh was estimated as 424,198,240 Rials (\$12,476).
Considering the exchange rate of 34,000 Rials per U.S. dollar, these calculations imply that each household is prepared to spend an equivalent amount of $\$ 9.47$ out of their total annual income for the conservation of myrtle forest resources, valued at around $\$ 12,476$.

\section{Discussion and conclusions}

Based on the results of our study, we come to the conclusion that the WTP per year per household and the conservation value per hectare in Dooreh were higher than those reported by Molaei and Kavousi Kelashmi (2011) and Khosravi and Sabouhi (2011). We suggest two reasons for this discrepancy: 1) traditional knowledge on the part of this rural community about value and potential of this species, as well as their awareness of the extent of the damage inflicted on the natural habitat of this species; 2) the increased benefits derived from the exploitation of myrtle in terms of additional seasonal income earned by the community from harvesting and selling this species and an appreciation for other environmental values of this rapidly vanishing plant. The local knowledge in the community about the medicinal value of myrtle is based on its traditional belief in and experience from the consumption of this species, as well as on the positive impact of employment and financial rewards in the manufacture of several medicinal products by the local pharmaceutical company. A fundamental problem in harvesting this species, however, is lack of proper skills in people involved in harvesting operation of this species, which has eventually led to the degradation of over half of its natural habitat.

In general, the local community now has a better understanding of how valuable myrtle is to them. Such an understanding has gradually been developed as the local people began to realize the extent of myrtle forest damage in their area and hence, the need for its conservation. In short, the main reason why local people are willing to pay something for conservation of their myrtle forest resources is entirely economical, since $86 \%$ of them are willing to pay some money for its conservation. The remaining $14 \%$ who were not willing to pay anything were apparently doing so for financial reasons, given their low level of income. Interestingly, for the same obvious reason, this latter group did not have a favorable response for the conservation of any other species either. This is the type of situation where the need to educate local people is felt the most, in order to enhance their understanding of environmental issues and the conservation of flora and fauna in their own community. Unfortunately, due to poor management, no effective policy has been proposed or implemented, despite its neglect over the years.

In this study, it was found that the annual WTP per household and the conservation value per hectare was 
lower from those reported by Lehtonen et al. (2003), Leong et al. (2005), Gurluk (2006) and Tao et al. (2012). Apparently this was because in our study several other economically valuable aspects of valuation, other than the medicinal value of myrtle, such as timber production, habitat, regulatory and information functions, were not taken into consideration. A relatively stronger currency, higher levels of average income and education could also have been mentioned as additional reasons for the higher WTP reported in their research. It is also worth mentioning that Leong et al. (2005) and Peron and Esmaeili (2010)) estimated the forest value based on per hectare per person in a given household, instead of household as a whole, which raises the estimated WTP per household per year.

In contrast, the estimated WTP per household per year and the conservation value per hectare estimated by us were higher than those mentioned by Echeverria et al. (1995) and Molaei (2009), apparently because these studies were more recent than those mentioned earlier. Clearly, this 20 year span together with inflation had a significant impact on lowering the nominal value in the local currency. In the present study, the respondents were primarily local people, whereas in earlier investigations, the respondents were not necessarily from the study area and as a result had a very low or even zero WTP.

In this study, the annual WTP per household and the conservation value per hectare were also lower from those reported by Chukwone and Okorji (2008). We cite as possible reasons the following issues: 1 ) the lower average income and education level of the respondents in the current study had both a significant and positive (impact on their willingness to pay; 2) valuation was based on only one NTFP, i.e., myrtle, instead of all the available NTFPs in the forest; each of which could have a further positive impact on the WTP on the part of the respondents due to their effect on the level of family income. This was consistent with the findings of Chukwone and Okorji (2008), except for the fact that in their study women had a higher WTP, primarily because they were more engaged with harvesting NTFPs than men and perhaps their higher WTP reflected a level of acknowledgment for the value of NTFPs on their part.

According to the explanatory variables of our model, as the respondents became better educated, their understanding of myrtle forests and the value of conservation of these resources became more profound, their WTP was higher. Therefore, it is expected that educating people about the importance and economic value of myrtle would increase their willingness to pay. In general, the higher their education, the higher their WTP and the more their tendency to preserve the environment. Similar results were found by Echeverria et al. (1995), Lehtonen et al. (2003), Leong et al. (2005), Tao et al. (2012), Chukwone and Okorji (2008), Peron and Esmeili (2010), Molaei (2009), and Khosravi and Sabouhi (2011).

Among the explanatory variables of the model, income levels had the highest impact on the elasticity of the willingness to pay. In other words, as incomes rise, the tendency to pay more for the conservation of the habitat of this species increased and as well, their opinion about environmental issues became more positive. This would probably indicate that implementation of appropriate financial incentives and policies with regard to rural economic development in the Dooreh forest areas and surrounding villages could lead to an improvement of economic conditions and employment in this rural community, which would then lead to an increase in their income and thus WTP to protect the myrtle forest area from further degradation. Education and income are two important factors with a significant impact on the opinion of rural people on environmental issues. With increasing income, the elasticity for the WTP to preserve their environment increased. In contrast, people with low incomes were rather more concerned to give priority to satisfy their basic needs. This results was consistent with what many investigators such as Echeverria et al. (1995), Lehtonen et al. (2003), Leong et al. (2005), Tao et al. (2012), Chukwone and Okorji (2008), Peron and Esmeili (2010), Molaei (2009), and Khosravi and Sabouhi (2011) had reported earlier.

Furthermore, smaller households with their relatively lower daily expenditures were willing to pay more for myrtle habitat conservation compared to larger households. All the same, if larger households had a higher level of income, they were also willing to pay more despite their relatively larger family size. Such a result is consistent with the findings by Tao et al. (2012), Molaei (2009) Peron and Esmeili (2010).

In general, economic hardship in the rural community living in or adjacent to the myrtle forest areas of Dooreh, induces people to rely on excessive harvesting of myrtle for additional income which eventually led to the degradation of nearly $50 \%$ of the natural myrtle forest resource (Karimi, 2012).

The rural households in the study region have traditionally been harvesting myrtle in publicly-owned forests for their own consumption as well as for earning additional income. The problems of poverty, unemployment and a difficult economic situation dominating the rural forest communities in the region are considered to be the major causes for illegal harvesting of myrtle and the rapid degradation of its habitat. As well, the gradual but illegal encroachment of agriculture in this forest area by local farmers has had a significant impact on the process of myrtle habitat reduction and destruction.

The fact of the matter is that only a small portion of the myrtle habitat is privately owned by local farmers, with the Iranian government owning most of it. Rural 
owners harvest myrtle inappropriately and without the necessary skills. Also, these people tend to trespass on government owned sites for illegal harvest of myrtle. For both reasons, severe destruction of the myrtle habitat is the consequence. As mentioned earlier, the root of the problem is socio-economic and deserves special attention by the local as well as regional forest manager Estimating the value of conservation of this myrtle habitat could provide strong incentive and justification for the authorities in the Iranian Forest and Range Organization to allocate sufficient resource to restore and/or conserve the habitat of this species. Unfortunately, so far forest management approaches and policy making and implementation by the government authorities have not been effective in solving the problem of illegal harvesting and or helping conservation and restoration of this myrtle habitat. Thus, the outlook for this species appears to be rather dim, unless prompt, strong and effective action is taken by the authorities and sufficient resources allocated to support such an action.

The results of this study emphasize the need and importance of formulating and implementing appropriate policies for myrtle forest conservation and restoration by the Iranian executive authorities and policy makers managing the natural resources of our country.

Although estimating the conservation value of myrtle forest highlights the importance of lowering degradation and deforestation of these resources, by itself this is not a sufficient for very obvious reasons. When the basic needs of rural people are not met and they suffer from insufficient income and poverty, they tend to put more pressure on natural resources and, in this case, damage the myrtle by excessive harvesting. This could eventually lead to a permanent loss of the few remaining myrtle sites and their conversion to agricultural land. In such a situation, the rural community would, by no means, be willing to spend money to maintain myrtle habitat, but would be more engaged in damaging it by excess harvesting and ultimately by converting it to agricultural land. Therefore, we believe it would be equally important to educate the local population about proper harvesting methods and management of this species by trained and knowledgeable individuals.

Although the current status of the myrtle habitat represents a serious threat to its continued existence, in the end we believe and conclude that with proper management and policies, such as restoration of the myrtle forest resources, together with necessary financial and administrative support, the present situation can be turned around into an opportunity for the provincial economy and an increase in employment.

\section{Endnotes}

${ }^{1}$ The exchange rate between Rial and US dollar at the time of publication of this article was 34,000 Rials per US dollar.
Competing interests

The authors declare that they have no competing interests.

\section{Authors' contributions}

Research leading to this paper supported by the Sari Agricultural and Natural Resource University, and financed primarily by the university division of Higher Education. Also the branch Office of Lorestan Province of Natural Resources provided significant help and assistance during the entire process of gathering field data and completing the required questionnaires.

Shortcomings and mistakes, if any, are the responsibility of the authors.

\section{Acknowledgements}

We would like to express our profound appreciation to the people of Dooreh for their hospitality and for being so receptive and cooperative during our entire field work. Our special thanks also go to the authorities and foresters in the Lorestan branch of the Office of Natural Resources for all the help and assistance provided during the entire process of gathering field data and completing the required questionnaires.

\section{Author details}

${ }^{1}$ Department of Forestry, Sari Agricultural and Natural Resource University, Sari, Iran. ${ }^{2}$ Department of Forest Sciences, Gorgan Agricultural and Natural Resource University, Gorgan, Iran. ${ }^{3}$ Department of Forestry, College of Natural Resources, Sari Agricultural Sciences and Natural Resources University, Sari, Iran. ${ }^{4}$ Department of Forestry, Faculty of Agricultural, University of Lorestan, Lorestan, Iran. ${ }^{5}$ Department of Agricultural Economics, Sari Agricultural and Natural Resource University, Sari, Iran.

Received: 5 April 2015 Accepted: 9 October 2015

Published online: 03 November 2015

\section{References}

Amiri N (1392). Economic Valuation of Myrtle (Myrtus communis L.) using market price, substitution cost, opportunity cost and Contingent Valuation methods (Case study: the city of Dooreh Lorestan Province). M.S. Thesis. Sari University of Agricultural Sciences and Natural Resources. Faculty of Natural Resources, p 84

Bateman I, Willis K (1999) Valuing Environmental Preferences, Theory and Practice of the Contingent valuation Method in the US, EU, and Developing Countries. Oxford University Press, New York, NY, pp 511-539

Bohm P (1972) Estimating Demand for Public Goods. An Experiment. Eur Econ Rev 3:111-130

Chukwuone NA, Okorji CE (2008). Willingness to pay for systematic management of community forests for conservation of non-timber forest products in Nigeria's rainforest region. Econ Poverty Environ Nat-Res Use, 117-137

Cochran WG (1977) Sampling techniques, 3rd edn. Whley and Sons, USA, p 428

Dahlberg A (1974) Geografisk rorlighet: Sociala och economiska effecter (Geographic mobility: social and economic effect). University of Umea Sweden, Department of Economics (in Swedish)

Echeverria J, Hanarahan M, Solorzano R (1995) Valuation of nonpriced amenities provided by the biological resources within the Monterverde Cloud Forest preserve, Costa Rica. Ecol Econ 13:43-52

Falconer J, Arnold JEM (1989) Forestry and food security. FAO Forestry Paper 90. Rome: Food and Agriculture Organization of the United Nations (FAO).

FAO Forestry (1999) Towards a harmonized definition of non-wood forest products. Unasylva 50(198):63-64, http://www.fao.org/docrep/x2450e/ x2450e0d.htm

Gunatilake HM, Senaratne DMAH, Abeygunawardena P (1993) Role of non-timber forest products in the economy of peripheral communities of Knuckles national wilderness area of Sri Lanka: A farming systems approach. Economic Botany 47(3): 275-281

Gurluk S (2006) The estimation of ecosystem services value in the region of Misi Rural Development Project: Results from a contingent valuation survey. J Forest Policy Econ 9(3):209-218

Hanemann WM (1984) Welfare evaluation in contingent valuation experiments with discrete responses. Am J Agr Econ 66:332-341.

Hanemann, MW (1985) Some issues in continuous and discrete response contingent valuation studies. North-eastern journal of Agricultural and Resource Economics, 14: 5-13 
Hanemann WM (1991) Willingness to pay and willingness to accept. How much can they differ? Am Econ Rev 81:635-647.

Karimi MA (2012) Investigating the most important degradation factors of myrtle (Myrtus communis L.) in Lorestan province (A case study in Chegnei forest area). Tehran Research Centre of Scientific-Applied University, Iran

Kengen S (1997) Forest valuation for decision making: Lessons of experience and proposals for improvement. Food and Agriculture Organization of the United Nations, No: 165

Khosravi M, Sabouhi M (2011) Estimating conservation value of tamarisk in Fahliyan river bank using by contingent valuation method. J Environ Sci 4:73-82

Lee C, Han S (2002) Estimating the use and preservation values of national parks tourism resources using a contingent valuation method. Tour Manag 23:531-540

Lehtonen E, Kuuluvainen J, Pouta E, Rekola M, Li C (2003) Non-market benefits of forest conservation in southern Finland. Environ Sci Policy 6:195-204

Leong PC, Zakaria M, Ghani ANA, Mohd A (2005) Contingent valuation of a Malaysian Highland Forest: non market benefits accrued to local residents. J Appl Sci 5(5):916-919

Lescuyer G (1996) Monetary valuation of the non-timber forest products (NTFPs): Does it contribute to determine a sustainable management of those resources? Paper presented at the 6th International Conference of the Association for the Study of the Common Property (IASCP), Berkeley, 5-8 June 1996 (mimeo.)

Lindal M (1994) A comment on the valuation of non-wood forest benefits In: Proceedings of a workshop on evaluation of forest benefits through a total evaluation of production, environmental and social functions of forests. Forest value. Pp. 71-89. Prague-Jiloviste, 13-16 September. United Nations Economic Commission for Europe/Food and Agriculture Organization of the United Nations (FAO)

Makkizadeh tafti M, Farhoodi R, Naghdi badi H, Mehdizadeh A (2006) Determining the best treatment for germination enhancement of three medicinal plants seeds: Rubia tinctourum L., Echinacea angustifolia D.C. and Myrtus communis L. Quart J Sci Res Med Arom Plants Iran 2:105-116

Molaei M, Kavousi Kelashmi M (2011) Estimating conservation value of Lilium ledebourii using contingent valuation method with double one-dimensional choice. J Agr Econ Dev 25:322-329

Molaei M (2009). The economic-environmental valuation of Arasbaran fores ecosystem. PHD Thesis, Department of Agricultural Economics, Faculty of Agricultural Economics and Development, Tehran University

Noubissie ET, Chupezi J, Ndoye O (2008). Studies on the Socio-Economic Analysis of socio-economic non-timber forest products (NTFPs) in Central Africa. Synthesis of reports of studies in the Project GCP/RAF/398/GER. Fao. Yaounde, Cameroon, FAO GCP/RAF/398/GER Enhancing Food Security in Central Africa through the management and sustainable use of NWFP: $p 43$

Park T, Loomis J (1996) Joint estimation of contingent valuation survey responses. Environ Res Econ 7:149-162

Pearce DW, Pearce CJT (2001) The Value of Forest Ecosystem. A Report to the Secretariat Convention on Biological Diversity

Peron S, Esmaeili A (2010) The estimated of non-market value mangrove forest in the Hormozgan province. J Agr Econ Dev 2:162-168

Peters CM (1994) Sustainable harvest of non-timber plant resources in tropica moist forest: An ecological primer. Biodiversity Support Program. World Wildlife Fund, The Nature Conservancy and the World Resources Institute. Washington, D.C.: World Wildlife Fund.

Piri M, Mosanane Mozafari M, Javdan A (2009) Estimating existence value of forests using willingness to pay of people (Case study: Forest of Arasbaran) J Forest Wood Prod Dept Nat Res 4:343-357

Rodda A (1991) Women and the Environment. London: Zed Books

Salehnia A (2008) Investigating medicinal and environmental importance of myrtle

Tao Z, Yan H, Zhan J (2012) Economic valuation of forest ecosystem services in Heshui watershed using contingent valuation method. Proc Environ Sci $13: 2445-2450$

Torras M (2000) The total economic value of Amazonian deforestation, 1978-1993. Ecol Econ 33:283-297

Venkatachalam L (2003) The contingent valuation method: a review. Environ Impact Assess Rev 24:89-124

White PCL, Lovett JC (1999) Public preferences and willingness to pay for nature conservation in the North York Moors National Park. UK. J Environ Manage 55:1-13

\section{Submit your manuscript to a SpringerOpen ${ }^{\circ}$ journal and benefit from:}

- Convenient online submission

- Rigorous peer review

- Immediate publication on acceptance

- Open access: articles freely available online

- High visibility within the field

- Retaining the copyright to your article

Submit your next manuscript at $>$ springeropen.com 